\title{
El alfar romano de Panxón (Nigrán, Pontevedra)
}

Un atelier romaine à Panxón (Nigrán, Pontevedra)

\author{
Rosa Villar Quinteiro \\ Doctora en Historia. Especialidad Prehistoria y Arqueología \\ rosavillarq@yahoo.es
}

\section{Resumen}

La actividad arqueológica preventiva llevada a cabo en la finca 6-8 de la Rúa Mirambel en Panxón (Nigrán, Pontevedra) ha permitido la localización y excavación de un taller de producción alfarera de cronología romana, totalmente inédito en el NO peninsular y que completa el pasado romano de esta villa costera. Dedicado a la producción de materiales de construcción y ánforas, ha aportado diversos graffitti identificativos que deberán ser rastreados entre los yacimientos geográficamente próximos.

\section{Palabras clave}

Alfar romano, ladrillos, tegulae, imbrices, ánforas, graffitti, Panxón.

\section{Résumé}

Les travaux archéologiques de prévention sur un terrain de la Rue Mirambel 6-8 au village de Panxón (Nigrán, Pontevedra, La Galice) viennent de permettre la découverte d'un atelier poterie á l'époque romaine, tout inédit au NO de la péninsule ibérique et que vient compléter le passé romaine de cette ville côtière. Centré sur la production des matériaux constructives et amphores, il nous apporte des exemples de graffitti pour l'identification des objets manufacturés sur les gisements de la région. L'étude des matériaux proposent une chronologie tardive, lors d'un long période d'activité commencé au II siècle dC.

\section{Mots Clé}

Atelier romaine, briquets, tegulae, imbrices, amphores, graffitti, Panxón, Galice.

\footnotetext{
Data de envío: abril 2014 Data de aceptación: febrero 2015
} 


\section{Presentación}

La finca objeto de trabajos de arqueología preventiva realizados durante el otoño de 2006 y verano de 2007, se encuentra ante la playa de la Madorra en la parroquia de Panxón (Nigrán, Pontevedra) y en el ámbito de protección de diversos yacimientos, como el de la Rúa do Arco (GA36035055), el BIC Arco Visigodo de Panxón (GA36035056) y del castro situado en el Monte del Castro (GA36035057); todo en la misma población. El solar tiene una superficie de $2.273 \mathrm{~m}^{2} \mathrm{y}$ forma rectangular, con topografía llana (Fig. 1).

En esta finca existió una edificación anterior, ocupando la zona central, además de otras estructuras de servicios: garaje con un pequeño túnel para el mantenimiento de coches, un estanque excavado en el terreno, dos pozos, un invernadero y una construcción exenta en la parte delantera de la finca.

Los objetivos se orientaron a la constatación de la presencia / ausencia de restos y/o evidencias arqueológicas. El trabajo se inicia con metodología manual en sondeos de 2x2m combinada con la apertura de zanjas con medios mecánicos. La aparición de registro arqueológico motivó la adaptación de la metodología a las nuevas circunstancias, por lo que se amplió la superficie de trabajo pasando a una excavación arqueológica en área.

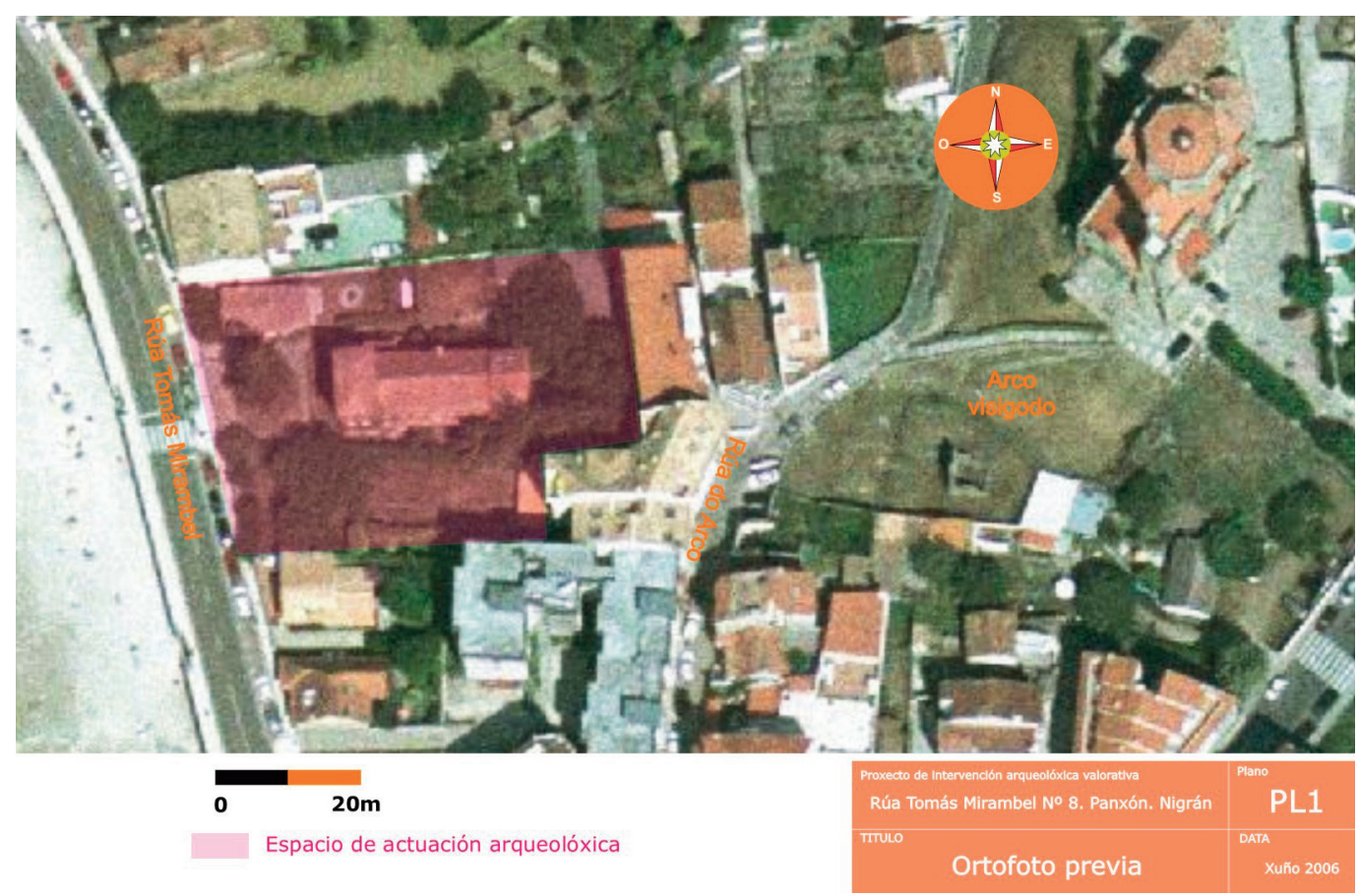

Figura 1. Localización de la finca (marcada en rojo).

\section{Estratigrafía}

A nivel estratigráfico los trabajos en área confirmaron la existencia de un único nivel arqueológico correspondiente al Nivel $3-52 \mathrm{~cm}$ de potencia-. Definido como un nivel arenoso de color gris oscuro, húmedo y compacto. Este nivel presenta estructuras y una 
componente orgánica, resultado de la ocupación antrópica que registra. Como consecuencia de la leve pendiente del terreno en dirección al mar -al Oeste-, este nivel va perdiendo potencia, lo que supone una mayor incidencia antrópica hacia el Este.

Según las características estructurales, en la formación del Nivel 3 podemos distinguir episodios: se inicia con una fase caracterizada por la presencia de abundante agua que produjo la sedimentación de los primeros $15 \mathrm{~cm}$ dominada por gravas y arenas entre una matriz de arenas gruesas, siendo frecuentes los moteados por oxidaciones. Al término de este ciclo, desaparecen las gravas en beneficio de las arenas finas y se produce la ocupación romana de este espacio, quedando sus restos materiales contenidos en el interior de este nivel arenoso. El Nivel 4 -subyacente- está constituido por una duna arenosa de color pardo amarillo, masiva y arqueológicamente estéril. En síntesis, la secuencia estratigráfica se caracteriza por (Fig. 2):

- Nivel 1: Horizonte edáfico de tierra negra pero con gran cantidad de arena. Este sería un horizonte antrópico formado por la acción del hombre contemporáneo. 40 cm de potencia.

- Nivel 2: Horizonte de naturaleza dunar, algo mezclado con la tierra del nivel superior pero en el que dominan las arenas. Contiene materiales modernos y ciertos fragmentos rodados de otros antiguos, posiblemente procedentes de remociones de tierras. $60 \mathrm{~cm}$ de potencia.

- Nivel 3: Horizonte de tierra gris muy arenosa que contiene las estructuras y restos materiales romanos. Horizonte antrópico, formado por la instalación de la población romana. $60 \mathrm{~cm}$ de potencia.

- Nivel 4: Duna arenosa masiva, potencia variable.

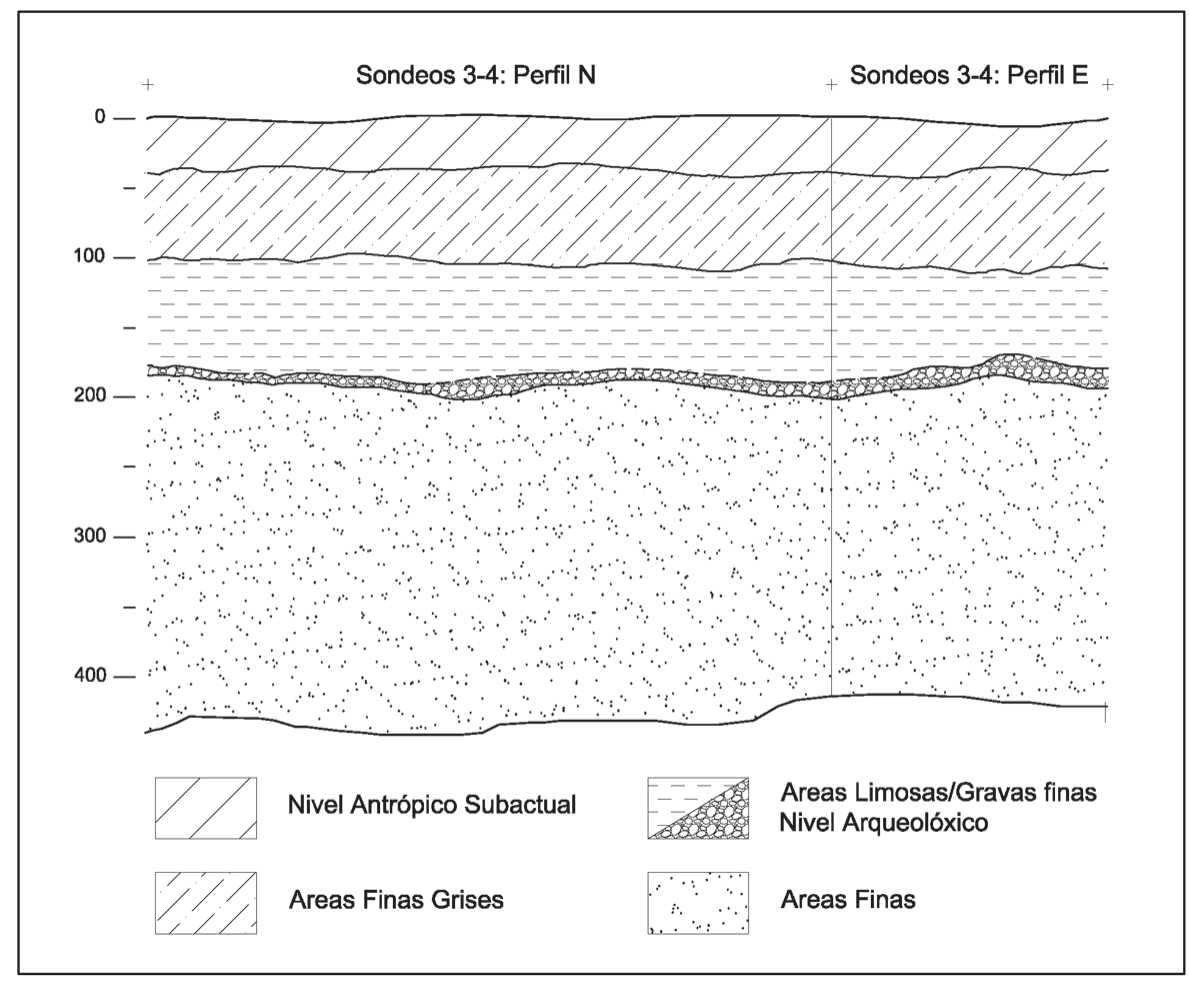

Figura 2. Estratigrafía. 
Las observaciones estratigráficas pueden resumirse en los siguientes aspectos:

- El nivel 3 es de naturaleza antrópica, mostrándose más potente en las áreas de mayor desarrollo de las estructuras -Este-, adelgazando en grosor hacia el Oeste y Sur.

- Secuencia estratigráfica claramente establecida e integrada por la sucesión de diferentes niveles de composición arenosa, de origen eólico -los superiores- o marina -capas limosas más bajas-.

\section{ESTRUCTURAS}

Las estructuras exhumadas son de diversos tipos y aparecen concentradas en la parte Este de la finca y en evidente relación espacial (Fig. 3, 4):

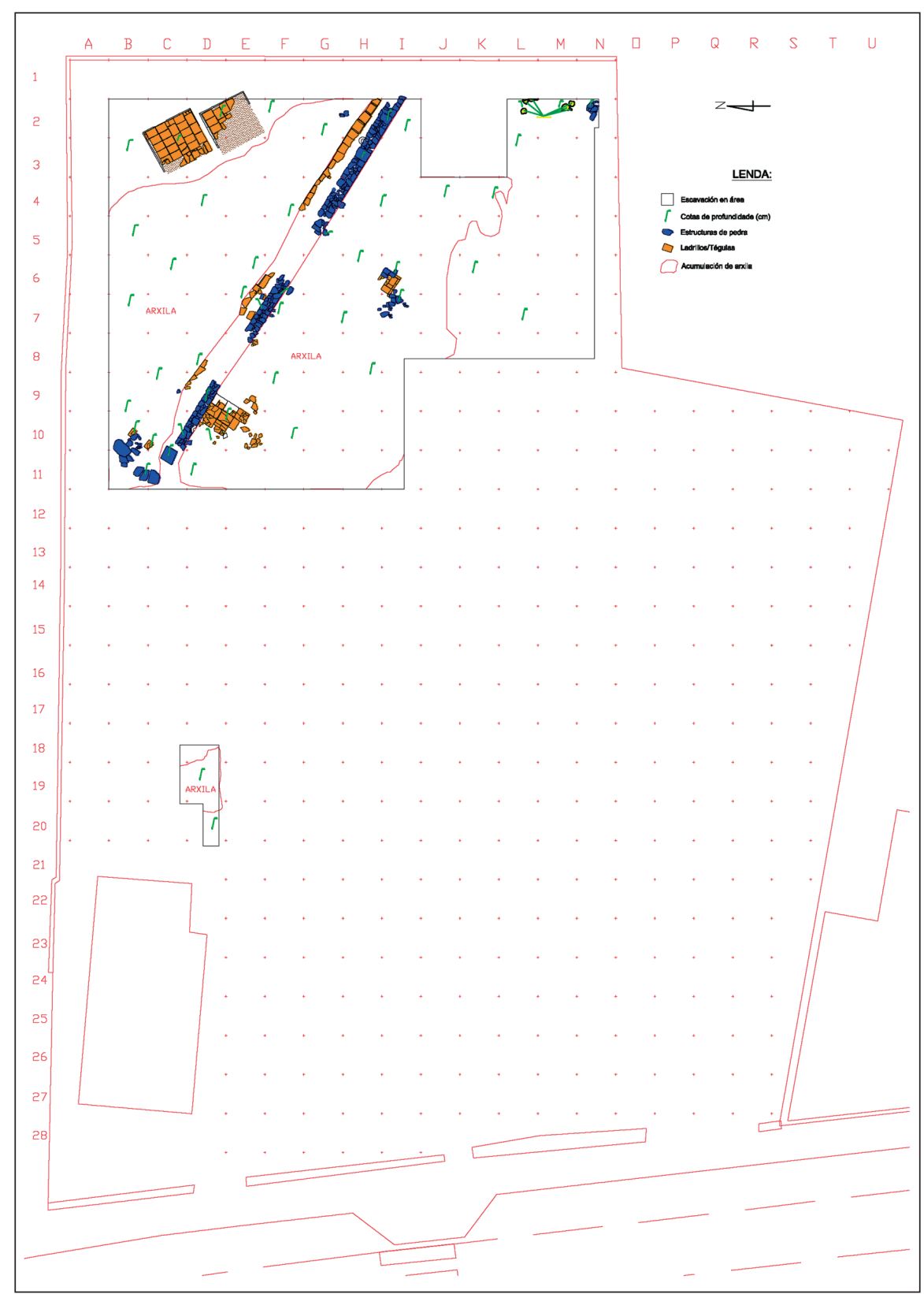

Figura 3. Planta de distribución de las estructuras. 

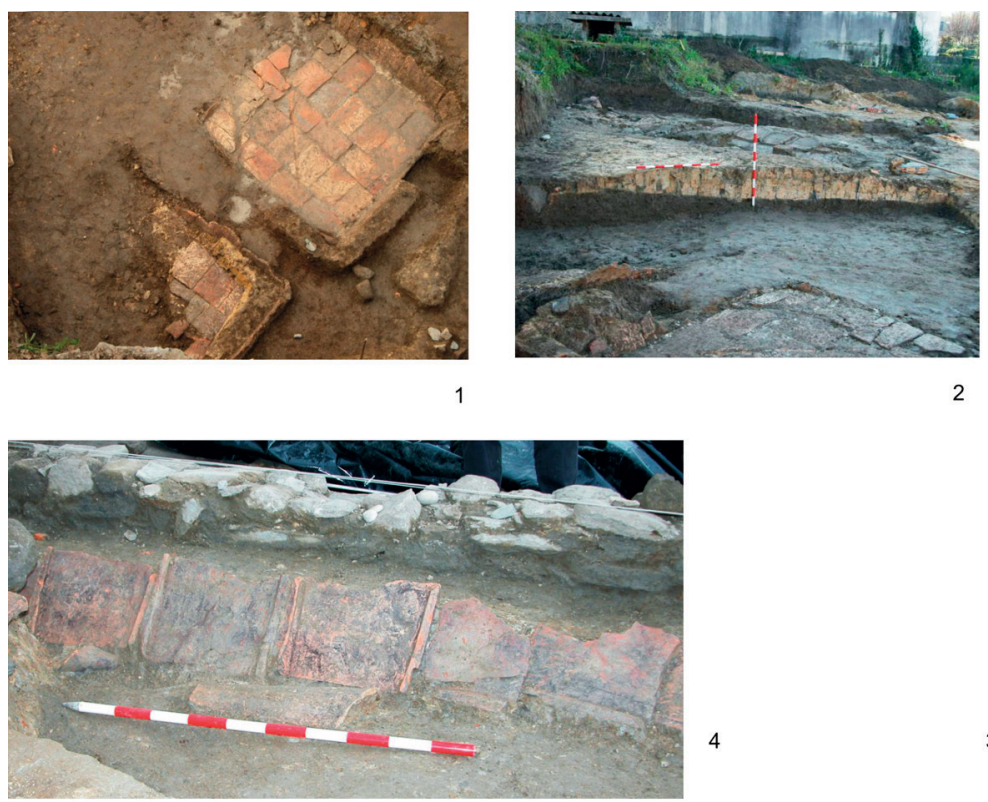

4
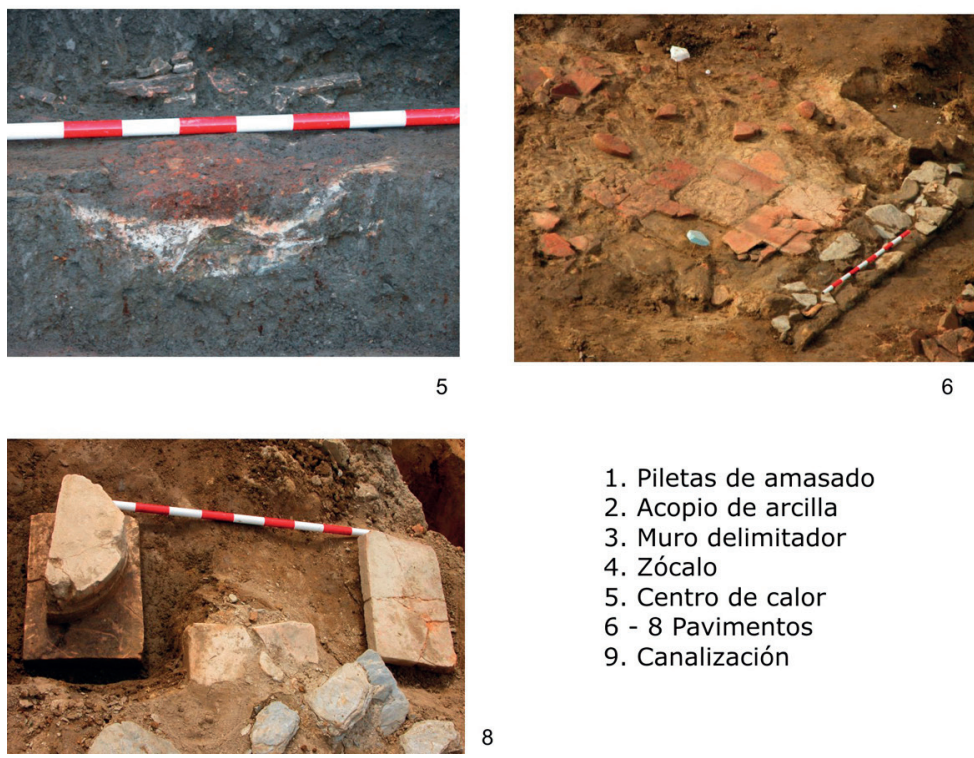

1. Piletas de amasado

2. Acopio de arcilla

3. Muro delimitador

4. Zócalo

5. Centro de calor

6 - 8 Pavimentos

9. Canalización
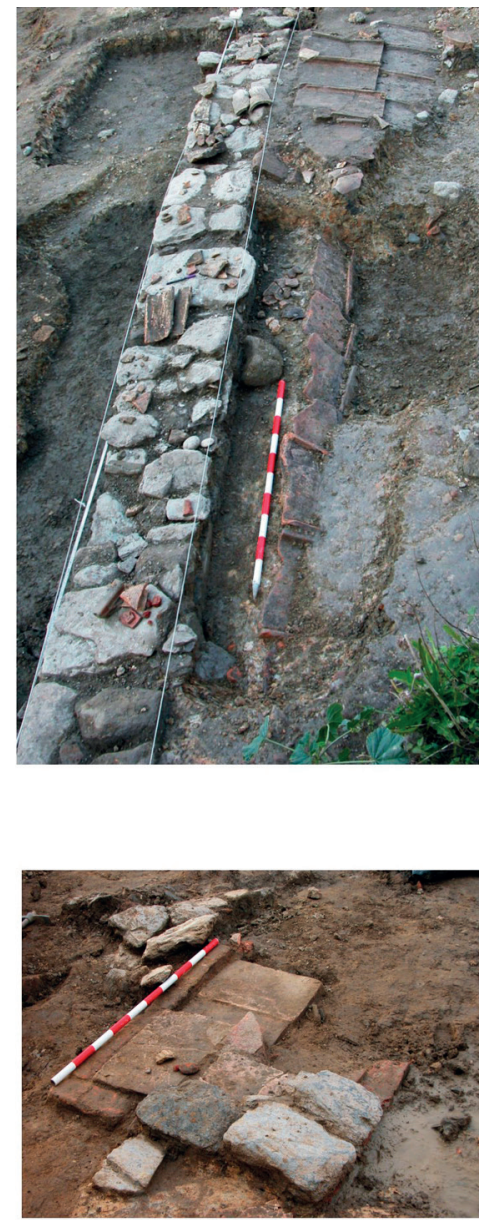

7

Figura 4. Fotografías de las estructuras documentadas.

\section{Las piletas de amasado de arcilla}

Los sondeos C-D/2-3 (Noreste) coincidieron con dos estructuras de ladrillo para el amasado y decantación de la arcilla, separadas entre sí 50cm, en una zona donde los últimos ocupantes de la finca habían construido el garaje y concretamente un túnel para el mantenimiento del coche; esta reciente estructura cortó la segunda pileta.

Construidas con adobes tipo lydium de 42×30x4 $\mathrm{cm}$ tomados con arcilla, tienen planta casi cuadrada y dimensiones semejantes: la más completa (A) tiene planta de 2x1,95xo,32 m, mientras que el lado conservado completo en la segunda (B) es algo más corto: $1,85 \mathrm{~m}$-. Tienen un zócalo perimetral ligeramente abierto que en el lado NE presenta un rebaje en la parte central, de 60cm de ancho (Fig. 4.1). Aparecieron colmatadas de arcilla muy pura y bien decantada, conteniendo fragmentos de piezas cocidas. 


\section{Acopios de arcillas}

De los tres depósitos de arcillas localizados, de origen antrópico, conteniendo abundantes fragmentos de teja y ánfora, destaca un enorme depósito asentado directamente en la arena base del Nivel 3, y perfectamente delimitado espacialmente, tanto en planta como en estratigrafía (Fig. 4.2). Se relaciona espacialmente con las piletas de amasado y decantación A y B (al N de este), así como con un muro delimitador de este espacio de trabajo (por el S) del que está separado por un zócalo formado por tejas planas -tegulae- apoyadas en el muro (Fig. 4.4). Estos acopios, se depositaron en bañeras abiertas en el suelo de ocupación. El más próximo a las piletas de amasado estaba parcialmente cubierto con tejas planas perfectamente colocadas para la captación de agua de lluvia (Fig. 4.3) con inclinación menor a $45^{\circ}$. Al igual que sucede con el muro, el zócalo pierde altura conforme avanza al Noroeste. Estos acopios corresponden a distintos tipos de arcillas, de tonalidades blanca o beige clara, gris, rosada rojiza.

\section{Muro delimitador de estancias}

Un muro lineal en dirección SE/NO aparece en los sondeos H-I/1 (Fig. 4.3) y se conserva hasta el cuadro B-9. Se trata de un paño de muro pétreo construido a base de piezas irregulares, de esquisto y granito -incluye fragmentos de molino circular de granito-, formando un aparejo rústico pero bien trabado, de $50 \mathrm{~cm}$ de ancho, conservado en 18,80 $\mathrm{m}$ de largo.

De $50 \mathrm{~cm}$ de altura en la zona Este, se asienta a una cota de 1,55 m si bien hacia el Noroeste pierde altura hasta quedar a la misma cota del suelo; esto está en relación con la general pérdida de potencia del nivel arqueológico conforme avanzamos al Oeste, a la playa.

Sin divisiones laterales, se remata en un bloque granítico paralelepípedo. Este remate coincide con otra área de revuelto por las obras contemporáneas. Al Sureste del muro documentamos áreas de derrumbes sobre un suelo de ocupación constituido por una fina capa de arcilla de $3-5 \mathrm{~cm}$ de grosor que se extendía uniforme a este lado del muro, sobre gravas y arenas, como elemento nivelador y aislante.

El importante grado de arrasamiento del lugar queda demostrado por este derrumbe constatado en particular. La presencia caótica de tegulae e imbrices -tejas curvas- hechos añicos en este sector central, así lo evidencia.

En medio de este derrumbe definimos una estructura pequeña, rectangular, compuesta de ladrillo en dos capas superpuestas -reforzada en el ángulo Nordeste con piezas de esquisto- y que se interpreta como un basamento para columna / viga de madera de sustentación de techumbre (Fig. 4.7).

\section{Centros de calor}

La extensión del trabajo a la esquina Sureste de la finca permitió la localización de restos de otro muro de piedra, solamente conservado en 40cm de largo, con dirección SE/NO (Fig. 3). En relación con este, apareció una estructura de calor de tipo cubeta excavada 
en la misma arena y gravas de la base del Nivel 3. De planta circular, de 6ocm de diámetro, está rellena con arcilla y una tegula cara abajo. La arcilla bajo la tegula presenta un aspecto claro de rubefacción. A la derecha, una zona de limpieza identificada por la concentración de carbones. A la izquierda, definimos otra estructura de calor semejante (Fig. 4.5).

\section{Pavimentos}

Podemos referirnos a restos de dos tipos de pavimentos. El primero se trata de un pavimento rústico constituido por fragmentos grandes de ladrillo y tegulae cara abajo. Este pavimento coincide con los cuadros $\mathrm{C}-\mathrm{D} / 9$ y sus dimensiones en origen serían superiores a las actuales -2 x 1,80 m-. Situado junto al muro por el lado Sur (Fig. 4.6), está asentado sobre un suelo de arcilla de $10 \mathrm{~cm}$ de potencia.

Otro resto de pavimento grosero apareció al Norte, al final del muro. Está constituido por losas de esquisto de tamaño medio / grande, asentadas sobre un piso de arcilla, conservando restos de un zócalo, también de esquisto. Presenta una superficie muy irregular (posiblemente relacionado con la inestabilidad del suelo natural arenoso). Este pavimento formaría parte de otro espacio diferenciado respecto del área de las piletas y los acopios de arcilla, conservando un acceso con puerta flanqueada por dos basas de pilar o columna, separadas $70 \mathrm{~cm}$ (Fig. 4.8).

Las bases están formadas por adobes de diferentes medidas:

- Ladrillo en la base: derecho (L: 43,6 cm, A: 30,5 cm, E: $7 \mathrm{~cm}$ ), izquierdo (L: $42 \mathrm{~cm}$, A: 28,5 cm, E: $5 \mathrm{~cm}$ ) (Fig. 5.1).

- Dos ladrillos semicirculares superpuestos y de idénticas dimensiones (Diámetro: 37,5cm, Espesor: $7 \mathrm{~cm}$ ) (Fig. 5.4).

Para su colocación se empleó arcilla en la base y estaban asentadas a $22 \mathrm{~cm}$ de profundidad respecto del enlosado relacionado con ellas. Teniendo en cuenta la altura del conjunto de estas piezas ( $21 \mathrm{~cm}$ en total), vemos que coinciden perfectamente con el plano marcado por el enlosado, de forma que el zócalo de pizarra venía a paño con la superficie de las bases. Por tanto estas basas, en su fase final se encontraban enterradas.

\section{Canalización}

En la mitad Sur de la finca se exhumó una estructura lineal, en dirección Este / Oeste, hecha con losas de esquisto. Dimensiones: $18 \mathrm{~m}$ de longitud y 0,70 $\mathrm{m}$ de ancho en planta. En los primeros $3 \mathrm{~m}$ por el Este, esta estructura no se conservaba completa, faltando tapas horizontales y en su lugar se apreciaba una alineación de piedras, discontinua -área revuelta por obras anteriores-. A partir de aquí y a lo largo de $15 \mathrm{~m}$ hacia el Oeste, la estructura estaba perfectamente conservada.

$\mathrm{Al}$ exterior estaba formada por lajas de esquisto de dimensiones medias $-40 \mathrm{~cm}$ de ancho- y formas irregulares -tendiendo a cuadradas o rectangulares-, colocadas unas junto a otras o incluso encabalgadas (Fig. 4.9; 6). 


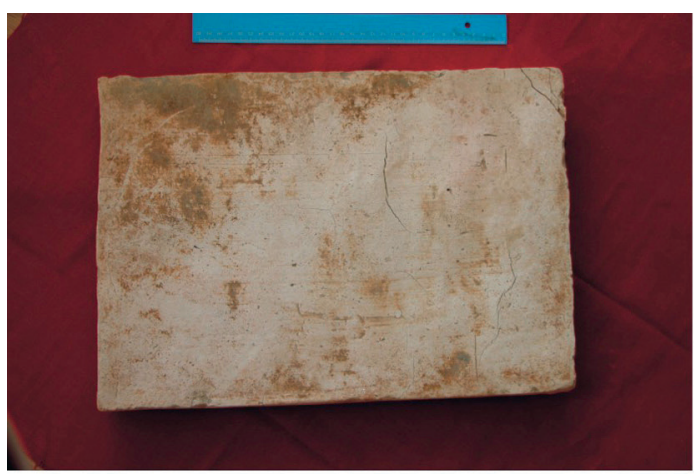

1

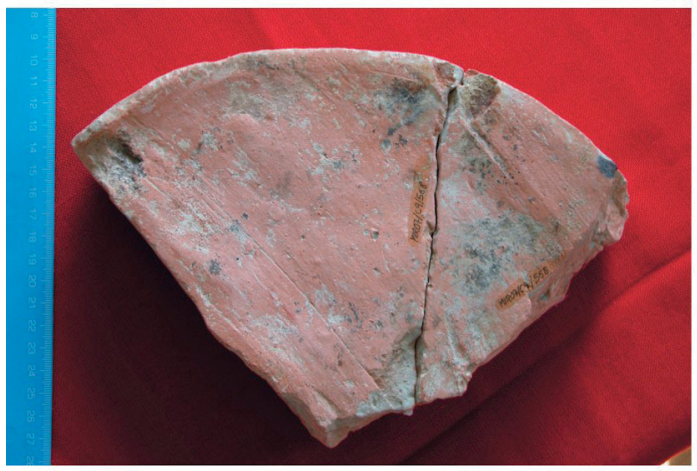

3

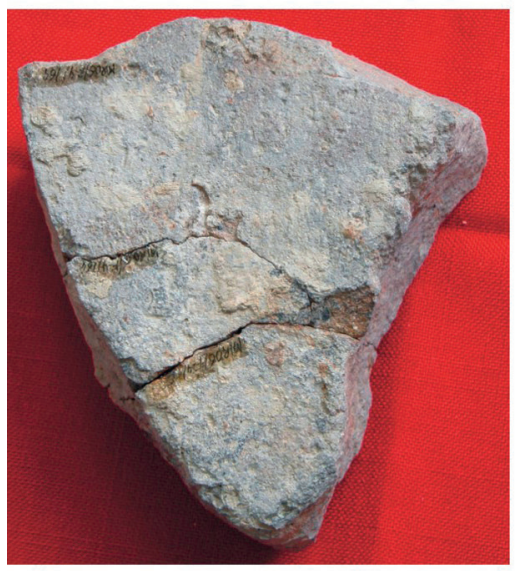

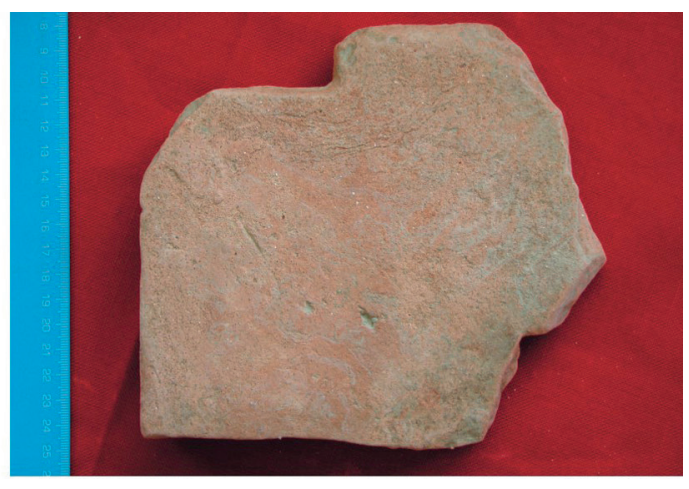

2

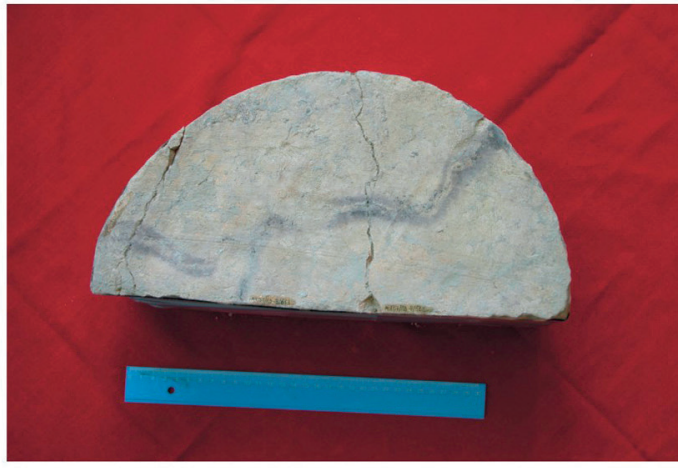

4

6

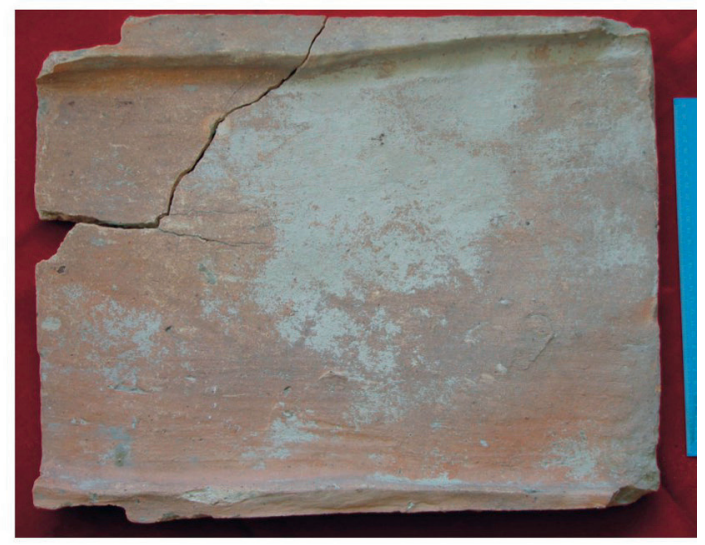

7

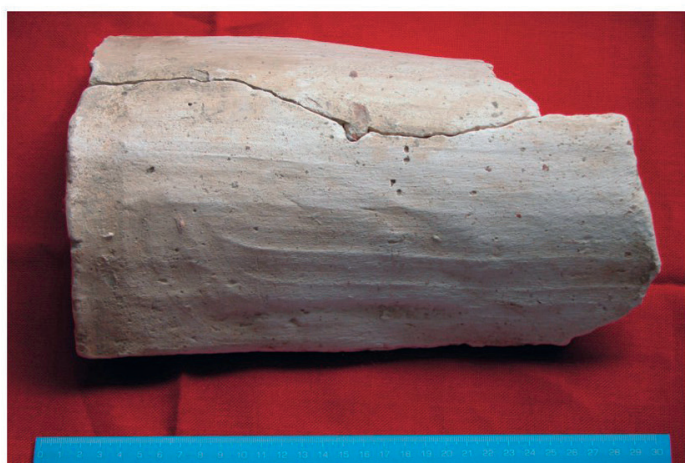

Figura 5. Materiales de construcción. 


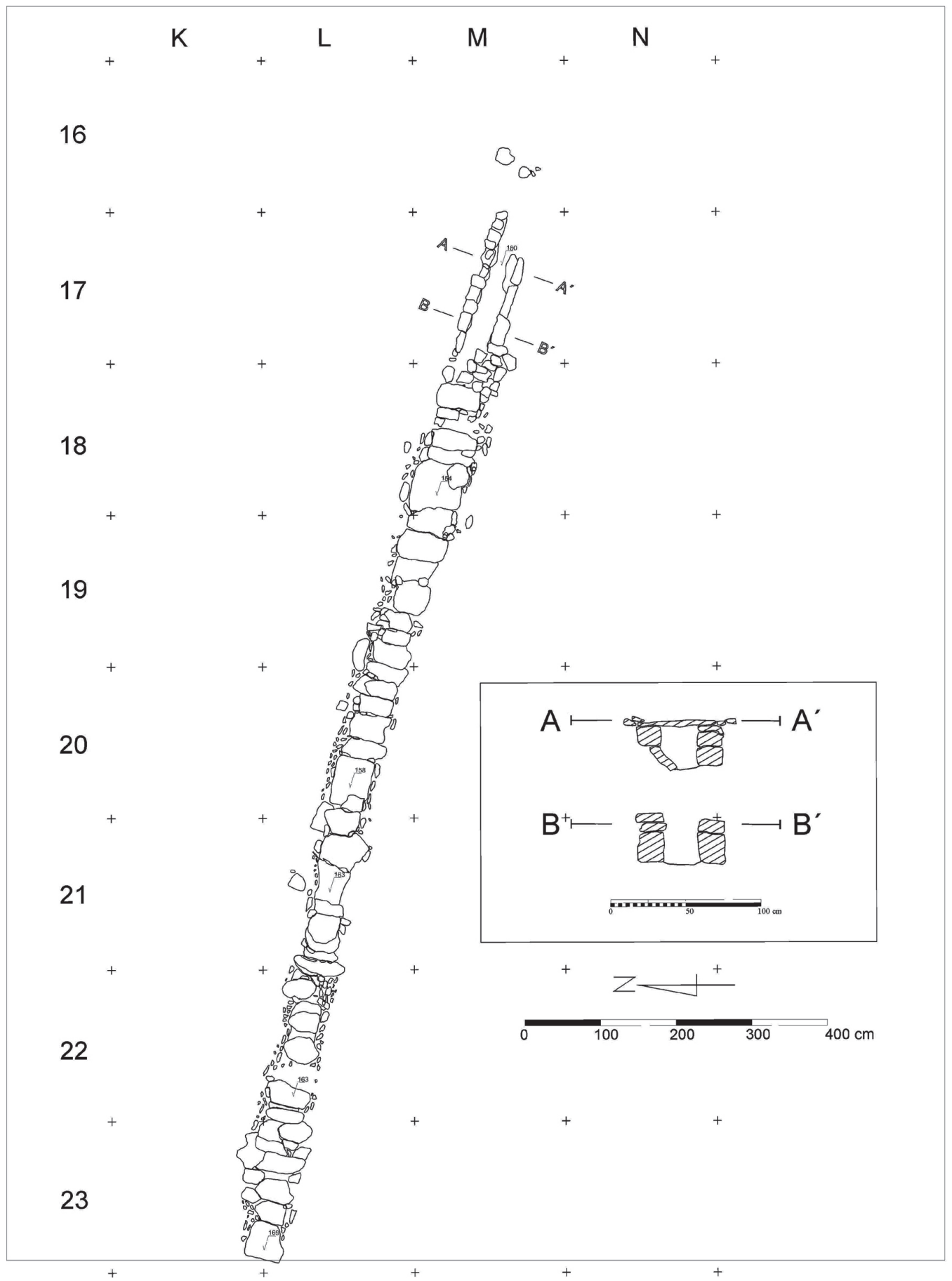

Figura 6. Planta y secciones de la canalización.

En el interior, la estructura era sencilla pero sólida, consistente en la apertura de un canal en la duna arenosa. Las paredes verticales se construyeron con piedras de tamaño medio -de esquisto / pizarra, granito, etc.- asentadas directamente en la duna, que en seco se endurece y compacta. Por encima, se añaden otras piedras pequeñas para completar huecos y sellar bien la unión con las tapas del canal, a base de losas de tamaño regular o varias más pequeñas con cantos rodados y fragmentos indeterminados de piezas de barro hasta obtener un sellado adecuado. 
Documentamos una canalización de $27 \mathrm{~cm}$ de alto por $22 \mathrm{~cm}$ de ancho -medidas interiores-, alcanzando el conjunto una altura de 45-50 cm desde la base hasta la superficie de la tapa.

Esta tajea estaba colmatada: de suelo a techo, un primer horizonte de arena gris, húmeda, que aportó escasos restos - pequeños fragmentos cerámicos de tipo común, esquirlas de huesos y restos de fauna marina consumida: percebe, navaja, almeja... junto a abundantes caracoles de tierra-, lo que indica una función como aliviadero de la zona doméstica del alfar.

Un segundo horizonte de arena color pardo-grisáceo. La presencia de micro-canalillos de precipitación de gravas y arenas en el relleno interior del canal informa del paso de aguas, confirmando su función como un canal de conducción de aguas muy posiblemente relacionado con el área de uso doméstico del alfar. El carácter doméstico se constata en dos tipos de restos identificados en su interior y que se relacionan con la alimentación y las cerámicas comunes de cocina, de características técnicas iguales a las recuperadas en el sector Este donde aparecieron restos de un centro de calor.

\section{Hornos}

Los trabajos no permitieron la localización de hornos para la cocción de los productos cerámicos -sin duda, fuera de los límites de la finca, hacia el Este-, pero si obtuvimos indicios de su existencia, sin poder determinar el número de estas estructuras.

Además de los centros de calor mencionados, que probablemente corresponden al infierno de los hornos, contamos con la presencia de varios ladrillos que claramente se relacionan con el mantenimiento de una estructura de horno con posible cubierta en forma de cúpula, según se desprende de la forma triangular de algunos de estos ladrillos (Fig. 5.5).

Realizados con pasta grosera con enormes y abundantes desgrasantes minerales, presentan un aspecto parcialmente vitrificado (resultado del calor soportado) y siempre quemado.

\section{LOS MATERIALES CERÁMICOS}

El número total de restos materiales recuperados es alto, a pesar del importante grado de arrasamiento del yacimiento. Contabilizamos un conjunto de 656 restos, para la interpretación del alfar. La composición de este lote de restos la aportan los materiales cerámicos diversos (97\%), junto con pequeños lotes de elementos pétreos, metálicos e incluso de fauna y alimentación.

En coherencia con el estado general de las estructuras, el estado de conservación de estos restos materiales es muy fragmentado, aspecto que dificulta la identificación de los tipos morfológicos de los recipientes. Su distribución espacial y relación con las estructuras documentadas, son indicios de las áreas de actividades del alfar ya comentadas. 
Restringiéndonos a los restos cerámicos, se advierte una importante diversidad de la producción del alfar: ánforas (38\%), material de construcción (27\%), cerámica común de cocina y mesa (30\%), además de otros restos indeterminados (3\%). Esta composición resulta coherente con la documentada en otras áreas peninsulares (véase por ejemplo: FABIÂO 2004; JUÁN TOVAR 1989; MORAIS 2005; MORAIS, FABIÂO 2007; REVILLA 1994).

\section{Ánforas}

Las ánforas aportan la mayor parte de los restos cerámicos recuperados, estando representadas diversas partes de estos recipientes. El análisis cuantitativo señala la siguiente distribución: fragmentos que conservan parte de la boca (12\%), asas (21\%), fragmentos del cuerpo (60\%), pivotes (6\%) y tapas (1\%).

La mayoría de estos restos muestran una pasta clara porosa de color beige, con degrasantes minerales y cerámicos. Con menor frecuencia aparecen pastas rosadas claras, naranja o rojas, muy decantadas y bien cocidas. Ocasionalmente conservan impermeabilizante interior en pastas claras y porosas o engobes exteriores en pastas rosadas o rojas.

$\mathrm{El}$ análisis de los fragmentos de boca permite definir diversos tipos:

- A) Ánforas tipo Dressel 14 lusitana occidental (Fig. 7).

Boca abierta rematada en labio de sección triangular o redondeado. Bajo la boca arrancan las asas, de sección aplastada y con un surco que recorre longitudinalmente el asa en la cara exterior. Son recipientes de cuello largo en los que el asa pegada, arranca bajo la boca, sin tocar el labio.
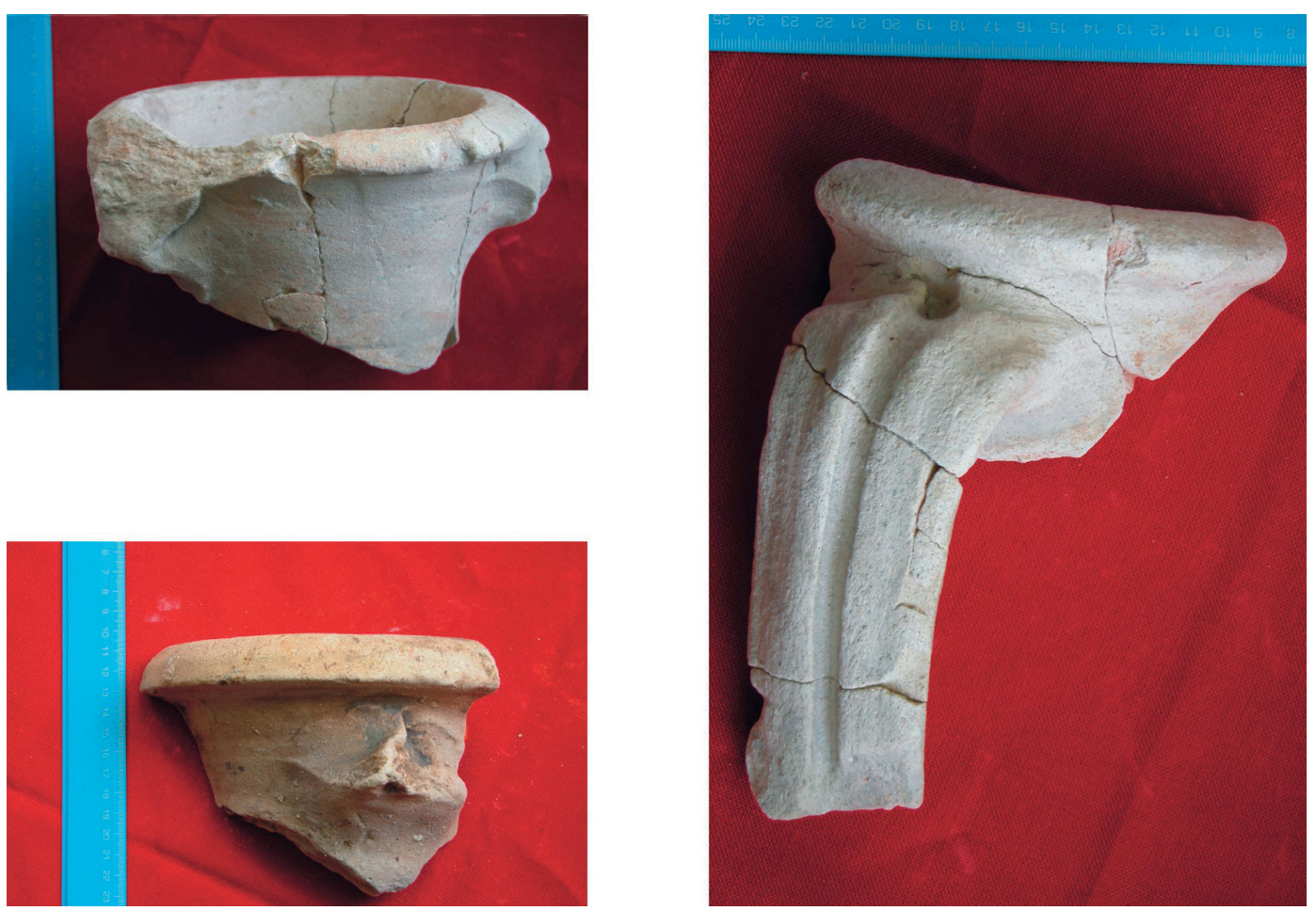

Figura 7. Ánforas Dressel 14 lusitana occidental, fragmentos de boca. 
Según la forma del labio, a partir del yacimiento de Pinheiro (Portugal) se puede establecer una evolución cronológica que relaciona las formas de labio triangular con la segunda mitad del S. I dC y las de labio redondeado con el final del S. II - III dC (FABIÂO 2004, 2008; MORAIS, FABIÂO 2007; CORDEIRO, VIEGAS 2013; BERNARDES, MORAIS, VAZ PINTO, DIAS 2013).

- B) Ánforas tipo Almagro 50 lusitana occidental -Lusitana 6- (Fig. 8).

Recipientes de labio liso del que directamente salen las asas, siendo anchas y gruesas, de sección circular, el diámetro disminuye conforme avanzan al extremo opuesto. En pastas bien decantadas con engobe rojo.
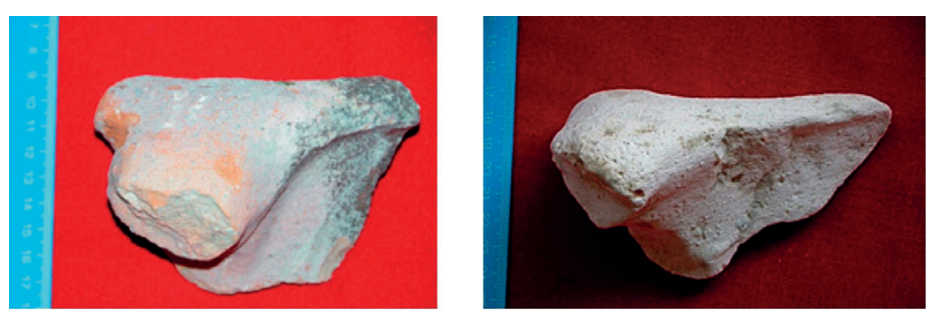

Figura 8. Fragmentos de ánfora tipo Almagro 50 lusitana occidental 5.
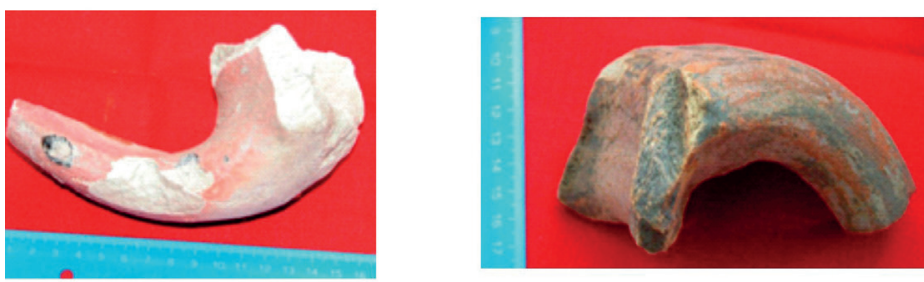

En Lusitania la producción de estos recipientes puede establecerse desde finales del S. II dC en el yacimiento de la Quinta do Rouxinol pero ya claramente establecida en los S. III y IV dC (ALMEIRA, CORDEIRO 2014). . En nuestro territorio se conocen piezas similares en los castros de Santa Trega, Vigo y A Lanzada.

- C) Ánforas Almagro 51C lusitana occidental -Lusitana 4- (Fig. 9).

Recipiente de cuerpo fusiforme identificado aquí por algún fondo cónico y posible boca con asas planas que parten justo de debajo de esta, cuello corto. Producidas en los valles del Tajo, Sado, costa del Algarve y la Bética, entre los S. III - V dC (Viegas, Cordeiro, Vaz Pinto 2014).
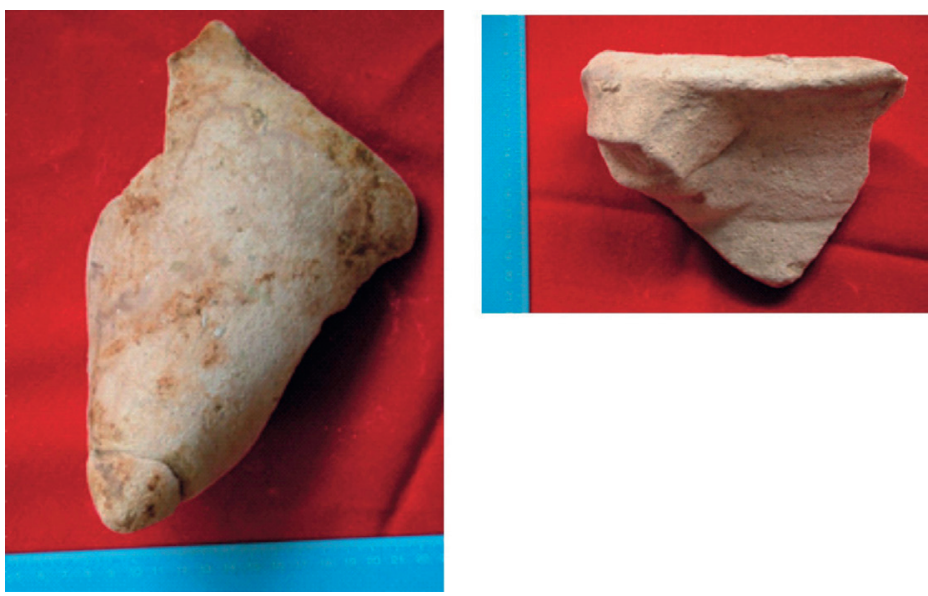

Figura 9. Fondo cónico y boca de ánforas Almagro 50C lusitana occidental 4. 


\section{- D) Ánforas Lusitana 9 (Fig. 10).}

La presencia de varios fondos planos y bocas de las que parten asas planas nos lleva a considerar la presencia de este tipo en Panxón: de borde ex vasado que puede ser engrosado, cuello solo marcado y asas planas que pegan en el borde y pueden tener surcos.

Documentada en los valles del Tajo y Sado, se establece su producción desde mediados del S. III al V dC.
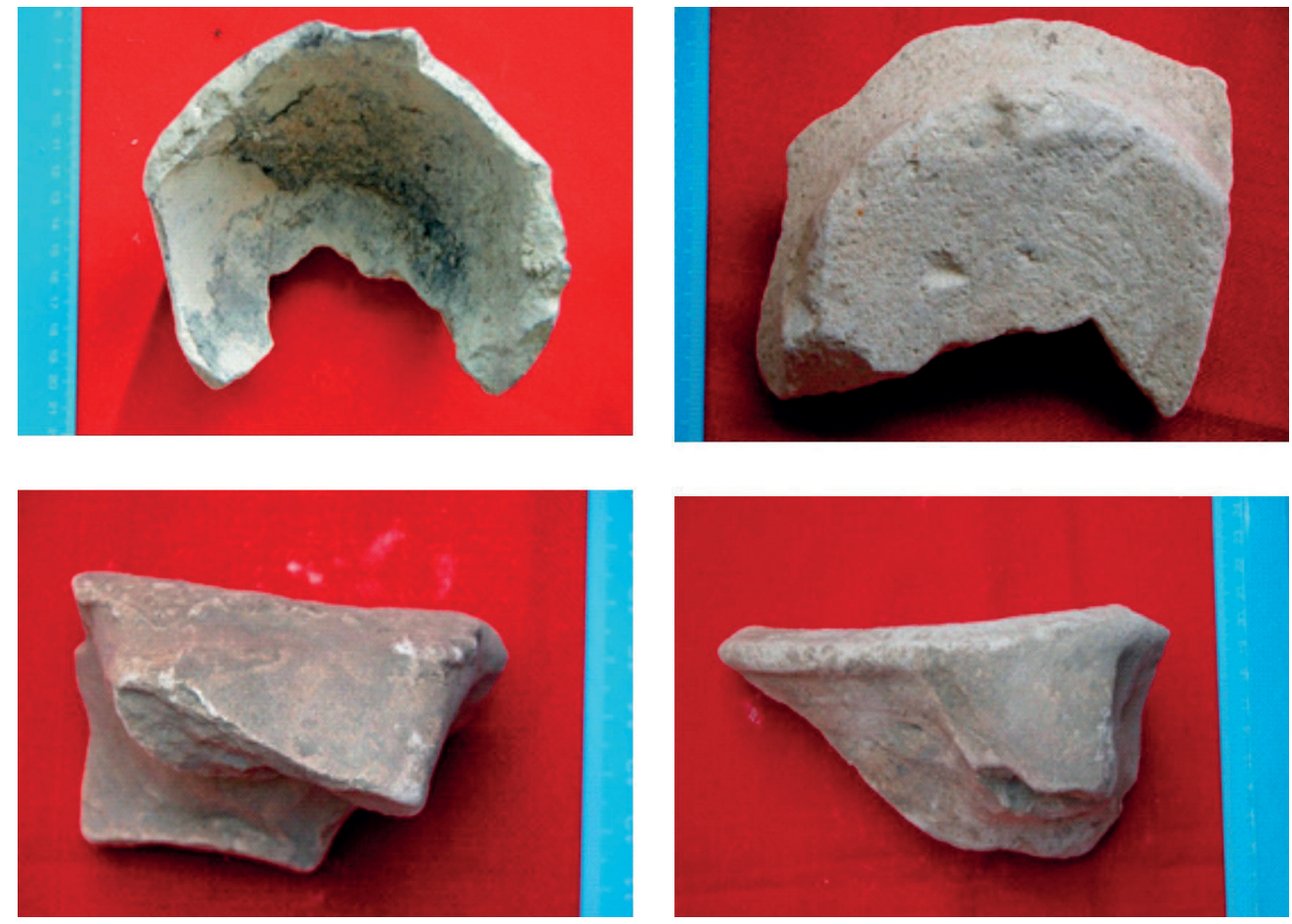

Figura 10. Fraǵmentos de ánfora lusitana 9.

Otros fragmentos como los pivotes tienen una representación menor pero resultan de gran valor para la reconstrucción formal de estas piezas. Como los anteriores, aparecen en pastas y morfologías diversas, destacando las pastas claras y particularmente de color rojizo, muy decantadas. Todos los fragmentos recuperados consisten en pivotes rellenos, excepto uno (Fig. 11). Las morfologías se ajustan a patrones conocidos: cilíndricos, cilíndricos en omphalus, troncocónicos, cónicos con remates lisos, cónicos con una arista incisa y definido por un botón (Fig. 9). Por tanto, las características de los pivotes apoyan la identificación de los tipos anfóricos comentados.

Entre los numerosos fragmentos de cuerpos de ánforas identificamos una marca de alfarero o graffitti (NAVEIRO 1985-86: 203), consistente en una incisión lineal fina en forma de $\mathrm{V}$ posiblemente acompañada de otro trazo cuyo pequeño tramo conservado se observa en la esquina inferior derecha del fragmento. Hecha con la pasta fresca (Fig. 12), este motivo aparece en ánforas localizadas en Vigo, Santa Trega, A Lanzada o el Castro do Neixón (NAVEIRO 1985-86), pero siempre en el pivote. Según este autor, aparecen en contextos datados del siglo I al II dC en las producciones hispanas, haciéndose comunes a partir del siglo III dC. 


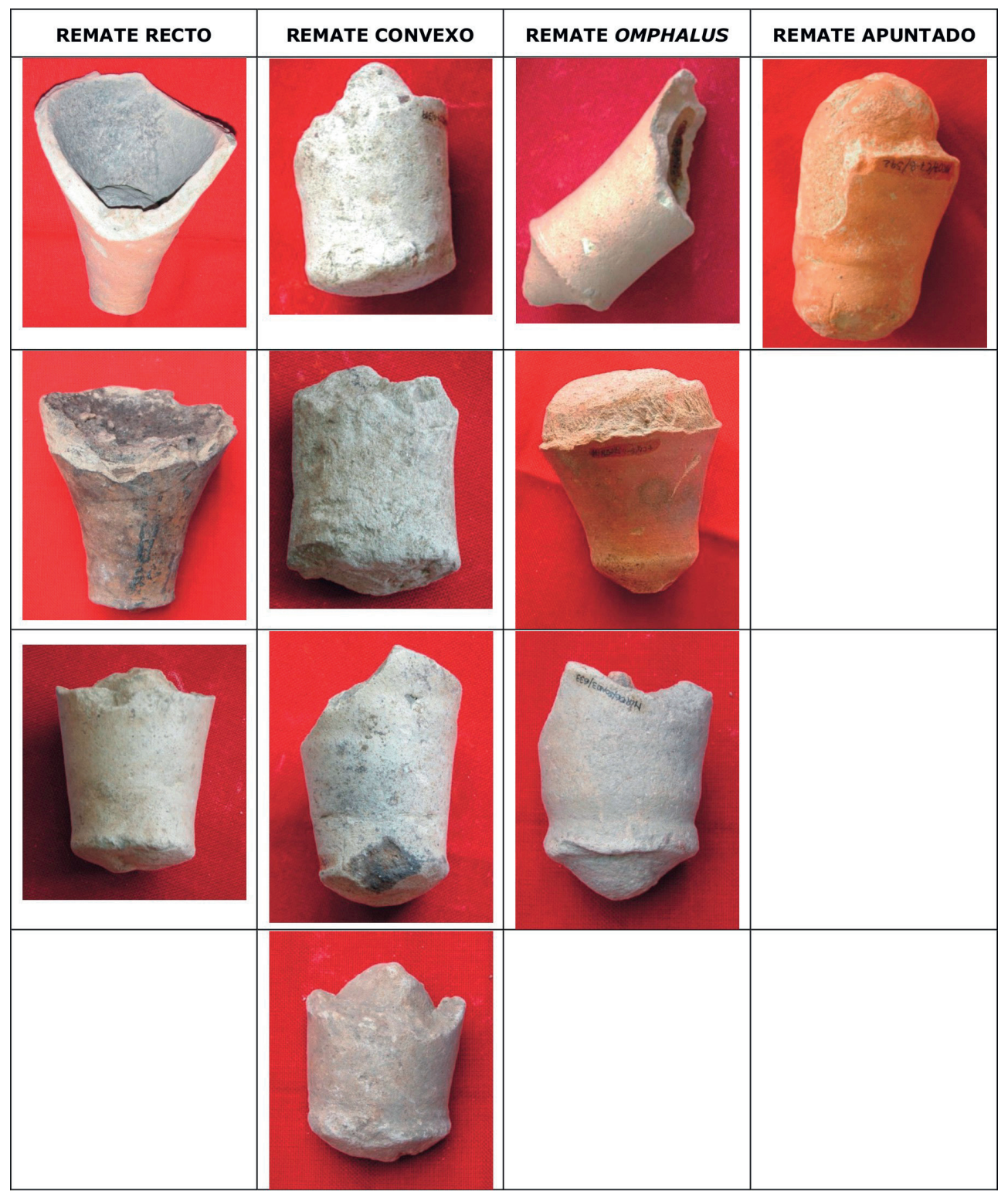

Figura 11. Remates de ánforas.

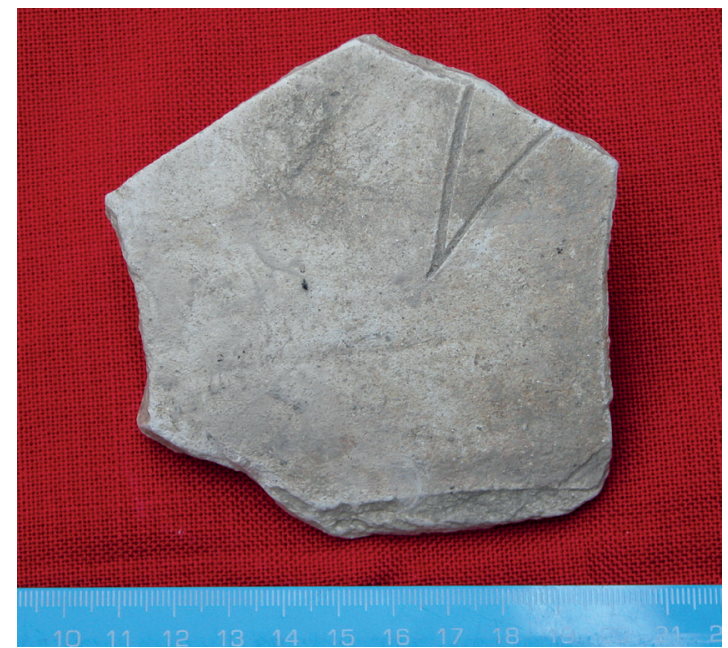

Figura 12. Fragmento de marca de alfarero. 
Otros elementos relacionados con estos recipientes son las tapas-opercula-, de forma circular, planas y con un pequeño apéndice en el centro como elemento de sujeción. Estas piezas comienzan a fabricarse a partir del S. II dC, con referentes en el NO peninsular.

Estos paralelos nos sitúan ante una producción anfórica de fuerte influencia lusitana a partir de un momento que pudo iniciarse a finales del S. I-inicios del II dC, manteniendo un largo período de actividad que pudo llegar hasta el S. V dC.

$\mathrm{Al}$ igual que en los alfares lusos de referencia, aquí también registramos una producción diversificada, que además de las ánforas incluye materiales cerámicos de vajillas de mesa, de cocina y materiales de construcción (FABIÂO 2004; CARDOSO, RODRIGUES 2005; BERNARDES, MORAIS, VAZ PINTO, DIAS 2013).

\section{Materiales CONSTRUCtivos}

Representan el 27\% del total de los restos recuperados y constituyen un grupo integrado por diversos tipos: tegulae o tejas planas (14\%), ladrillos (7\%), imbrices o tejas curvas (6\%) (Fig. 5).

Las tejas planas -tegulae- son las mejor representadas y muestran buenas pastas de arcillas rosadas, castañas o ligeramente rojizas, siendo estas las más decantadas (Fig. 5.6). La presencia de ejemplares completos permite conocer las medidas de los dos ejes (LxA) facilitando la definición del tipo (Tab. 1).

\begin{tabular}{|c|r|r|r|r|r|}
\hline Sigla & \multirow{2}{*}{ L (cm) } & \multirow{2}{*}{ A (cm) } & \multirow{2}{*}{ E (cm) } & \multicolumn{2}{|c|}{$\begin{array}{c}\text { BORDE } \\
\text { Alto }\end{array}$} \\
\hline 489 & 51,5 & 41,5 & 2,9 & & \\
\hline 490 & 52,5 & 42 & 2,6 & & \\
\hline 501 & 52,5 & 41,7 & 2,6 & 5,8 & 3 \\
\hline 529 & 52 & 40 & 2,9 & & \\
\hline 578 & 53 & 42,5 & 3 & 5,2 & 3,3 \\
\hline 587 & 54,5 & 40,5 & 3,4 & 5,4 & 3,4 \\
\hline $\begin{array}{c}\text { Valores } \\
\text { medios }\end{array}$ & 52,6 & 41,36 & 2,9 & & \\
\hline
\end{tabular}

Tabla 1. Lista de tejas planas completas y sus medidas.

Se definen como tejas con sistema de encaje universal, caracterizadas por un reborde decreciente con engarce superior por la interrupción de este reborde y encaje inferior mediante el entalle de toda la altura del reborde. Las características métricas del reborde (superior a $5 \mathrm{~cm}$ ) puede ser un indicador de producciones hechas entre los S. I-III dC (PÉREZ LOSADA 1993: 251).

Los imbrices o tejas curvas aparecen muy fragmentados, sólo contamos con un ejemplar completo. Casi siempre presentan digitaciones en la cara externa consistentes en cuatro surcos paralelos que rematan en curva, resultantes de arrastrar por la superficie fresca de la pieza los cuatro dedos de la mano (excepto el pulgar) (Fig. 5.7). 
Los ladrillos también aparecen casi siempre fragmentados, pero no obstante es posible definir diversos tipos según las medidas (PÉREZ LOSADA 1993). Siempre son piezas de muy buena pasta: color rojo o castaño oscuro, muy bien decantada.

- Relacionados con el tipo Lydium. Ladrillos empleados en la construcción de las piletas de decantación $(42 \times 30 \times 4 \mathrm{~cm})$.

- Otro tipo presenta mayor grosor (Plancha 6.1) pero dimensiones semejantes: 43,5 x $31 \times 6,3 \mathrm{~cm}, 42,5 \times 28,5 \times 4,5 \mathrm{~cm}$.

- Un fragmento de ladrillo con entalle, de 2,5cm de grosor (Fig. 5.2).

- Cuadrante o pieza equivalente a $1 / 4$ de círculo, de dimensiones: $20 \times 17 \times 6,3 \mathrm{~cm} \mathrm{y}$ 17x17x6,1cm (Fig. 5.3).

- Mitad de círculo, de dimensiones: 43,5 x 30,5 x 6,2cm (Fig. 5.4).

- Una pieza incompleta pero que informa de otro tipo, más estrecho y alargado $(13,5 \mathrm{~cm}$ de ancho x 5,4cm de grueso).

Estos elementos de construcción evidencian una producción diversificada, dirigida tanto al mercado como al mantenimiento de las estructuras del propio centro alfarero, especialmente de los hornos (Fig. 5.5).

\section{LAS CERÁMICAS COMUNES}

Entre la producción de este centro cerámico también identificamos un corpus de cerámicas comunes de mesa, cocina y en general, para el consumo doméstico, que representan el 33\% del conjunto total de los restos materiales cerámicos recuperados.

Podemos señalar una concentración espacial en la distribución de las cerámicas comunes, en el área arrasada situada al Sur del muro divisor de áreas de actividad, lo que en parte explica la gran fragmentación de las mismas.

Se aprecia el empleo de pastas grises o beige grisáceas claras con abundantes y minúsculos degrasantes minerales - micas- quizá relacionadas con producciones de tradición indígena; además de otras de pastas ocre naranja, rojizas u ocres rosadas, muy bien decantadas y buena cocción.

Entre las cerámicas comunes de uso doméstico identificamos formas correspondientes a jarros y en particular de boca trilobulada y asa (tipo J4) (ALCORTA IRASTORZA 2001: 287). Destinados al servicio auxiliar de cocina, la cronología de estos jarros se situaría entre el S. II-IV dC. Otras piezas como cuencos pueden tener tratamientos sencillos de las superficies -estriados horizontales- o elementos formales característicos, como borde oblicuo. Las formas globulosas resultan frecuentes, con cuellos marcados y bocas de labios lisos abiertos, planos.

En este grupo de cerámicas comunes destaca un recipiente de tradición indígena, de pasta beige clara con desengrasantes micáceos, posiblemente para contener líquidos y que apareció exento, próximo a los centros de calor. De fondo plano, el arranque del cuerpo es muy abierto, con hombros altos donde presenta el diámetro máximo $(55 \mathrm{~cm})$; el cuello es cerrado y algo desarrollado, terminando en boca apenas abierta, de labio liso, 
horizontal. Destaca por su decoración plástica a base de aplicaciones de cordones con incisiones oblicuas: en cuello -horizontales- y en los hombros -verticales- (Fig. 13). Esta decoración en relieve mediante cordones y la técnica de la incisión son aspectos característicos de la cerámica castreña de las Rías Bajas ya desde la fase media de su desarrollo (REY CASTIÑEIRA 1990-91: 150). Estas piezas formarían parte del menaje doméstico de los trabajadores del alfar.

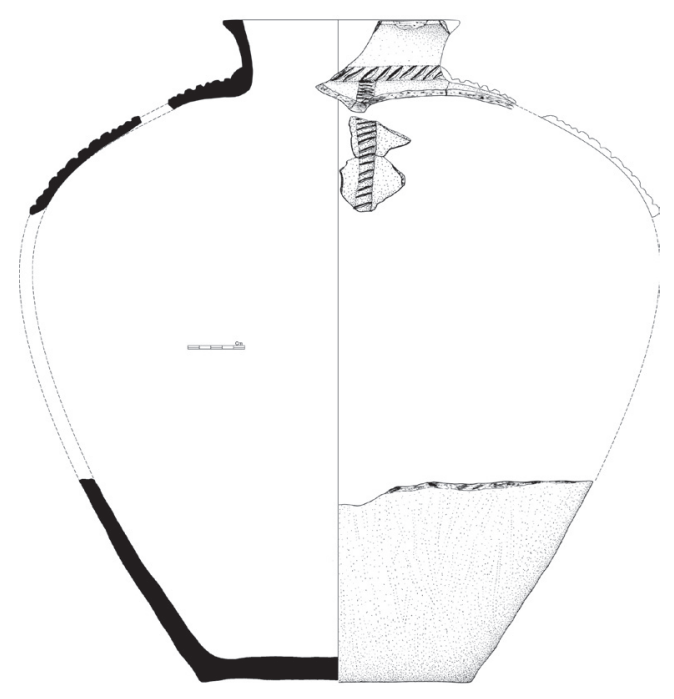

Figura 13. Recipiente de tradición indígena.

Otras cerámicas de servicio de mesa, están menos representadas y aparecen igualmente fragmentadas. Para su elaboración se emplearon pastas más decantadas, sin degrasantes visibles, de colores beige, castañas, naranja o rojas, de buena calidad. Pueden tener tratamiento de las superficies -engobes- o no, pero no localizamos motivos decorativos. Esta constituiría una producción para el comercio. Según las morfologías, podemos distinguir platos / fuentes -con pié resaltado-y cuencos: fragmento de pié de plato de imitación Drag. 15/17, de los que se conocen algunos ejemplos en Lugo, en el S. III dC (ALCORTA IRASTORZA 2001: 365) aunque estas producciones se inician antes. En el Noroeste aparecen con cierta frecuencia y tempranamente, en general consideradas procedentes de Portugal. No tienen decoración pero si un engobe rojizo. Posible cuenco de fondo resaltado, cuerpo hemi-esférico y borde que puede ser horizontal o engrosado, de los tipos C1 o C3 de (ALCORTA IRASTORZA 2001: 327) y que sitúa en el S. II dC.

Solamente encontramos un pequeño fragmento de terra sigillata pero que por sus minúsculas dimensiones, no permite mayores apreciaciones, además de escasas evidencias de cerámicas de paredes muy finas, semejantes a las conocidas como de "cáscara de huevo". Se trata de pequeños fragmentos de cerámicas de pastas beige muy decantadas y de grosor no superior a 2-3 mm. Una situación similar se describe en el yacimiento de Peniche (Portugal) en el S. II dC (CARDOSO, RODRIGUES 2005).

Piezas de uso doméstico, como las lucernas están escasamente representadas y también a través de pequeños fragmentos, por su baja representación consideramos que podían tratarse no tanto de piezas producidas para el comercio como para uso propio de los trabajadores del centro cerámico. 
Parece evidente que la producción de cerámica de uso doméstico también formaba parte de la actividad del alfar en el que todo indica que imitaba tipos bien conocidos y de amplia distribución peninsular.

\section{Grafitos (GRAFFITTI)}

Los grafitos o graffitti son marcas muy frecuentes en los materiales cerámicos del Noroeste y que normalmente representan letras o números. Entre los materiales de construcción producidos en este alfar encontramos digitaciones o marcas hechas con los dedos, por parte de los operarios, con la pasta aún fresca. La ejecución y finalidad de estas digitaciones aparece aquí en diversas soluciones:

a) Acciones intencionadas para personalizar/identificar la producción. La interpretación de estas marcas no es clara, hay autores que las consideran como marcas del operario del alfar para poder tener un control de la producción de cada trabajador, mientras que otros consideran que son usadas en talleres de uso comunitario para distinguir la producción de cada casa (NAVEIRO 1985-86: 211).

b) Marcas no intencionadas, resultantes de la manipulación de la pieza mientras la pasta está fresca, pueden coincidir en una misma pieza con la marca intencional. Interesantes porque recogen la huella real de los dedos, dando una idea del tamaño, pudiendo deducir que estos operarios tenían dedos finos y quizá no grandes: individuos juveniles?.

c) Marcas fortuitas no antrópicas: consisten particularmente en huellas de perro o gato producidas por el paso del animal durante el período de secado o pre - cocción en el que las piezas, aún frescas, están expuestas al sol. En ocasiones incluso se combinan huella de perro y digitaciones.

d) Otro tipo de marcas aportan información climatológica. Posiblemente durante la exposición de las piezas frescas al sol, se produjo una inesperada tormenta de lluvia con granizo, dejando la superficie de la pieza -tegula-, con aspecto picado de cada gota o grano de hielo recibido, convirtiéndose así en un documento de registro climático.

El estudio de las marcas evidencia aspectos técnicos y morfológicos (Tab. 2, Fig. 14).

\begin{tabular}{|c|c|c|c|}
\hline TÉCNICAS & TIPOS MOFOLÓGICOS & SOPORTES & FIGURAS \\
\hline \multirow{2}{*}{$\begin{array}{l}\text { Incisión: } \\
\text { Mediante el uso de punzón, } \\
\text { elemento vegetal o arrastre del } \\
\text { dedo sobre la superficie de pasta } \\
\text { fresca. }\end{array}$} & $\begin{array}{l}\text { Letras mayúsculas: V, P, S, N, entre otras } \\
\text { posibles (L?) }\end{array}$ & $\begin{array}{l}\text { Tegulae, ladrillos, fraǵmento de } \\
\text { ánfora }\end{array}$ & $\begin{array}{l}\text { Figura } 14 \text {, motivos } 1,6,7 \mathrm{y} \\
\text { posible en } 8\end{array}$ \\
\hline & $\begin{array}{l}\text { Trazos lineales, curvos, paralelos o } \\
\text { no }\end{array}$ & Tegulae, imbrices y ladrillos & $\begin{array}{l}\text { Figura } 14 \text {, motivos } 2,3 \text {, } \\
4,6,7\end{array}$ \\
\hline $\begin{array}{l}\text { Impresión: } \\
\text { Digitaciones: aplicación directa } \\
\text { de dedos / huellas animales } \\
\text { sobre la pasta fresca }\end{array}$ & $\begin{array}{l}\text { Particularmente muestran huellas de } \\
\text { animal e impresión de yemas de dedos, } \\
\text { alta frecuencia de marcas fortuitas } \\
\text { durante el secado. } \\
\text { Pueden combinar ambos tipos }\end{array}$ & $\begin{array}{l}\text { Tegulae más comunes pero } \\
\text { también en ladrillos }\end{array}$ & $\begin{array}{l}\text { Fiǵura } 14, \text { motivos } 5 \text {, } \\
\text { parcialmente } 8 \text { y } 9-17 \text {, } \\
\text { ambos inclusive }\end{array}$ \\
\hline
\end{tabular}

Tabla 2. Esquema de síntesis de los graffittis documentados en el yacimiento. 


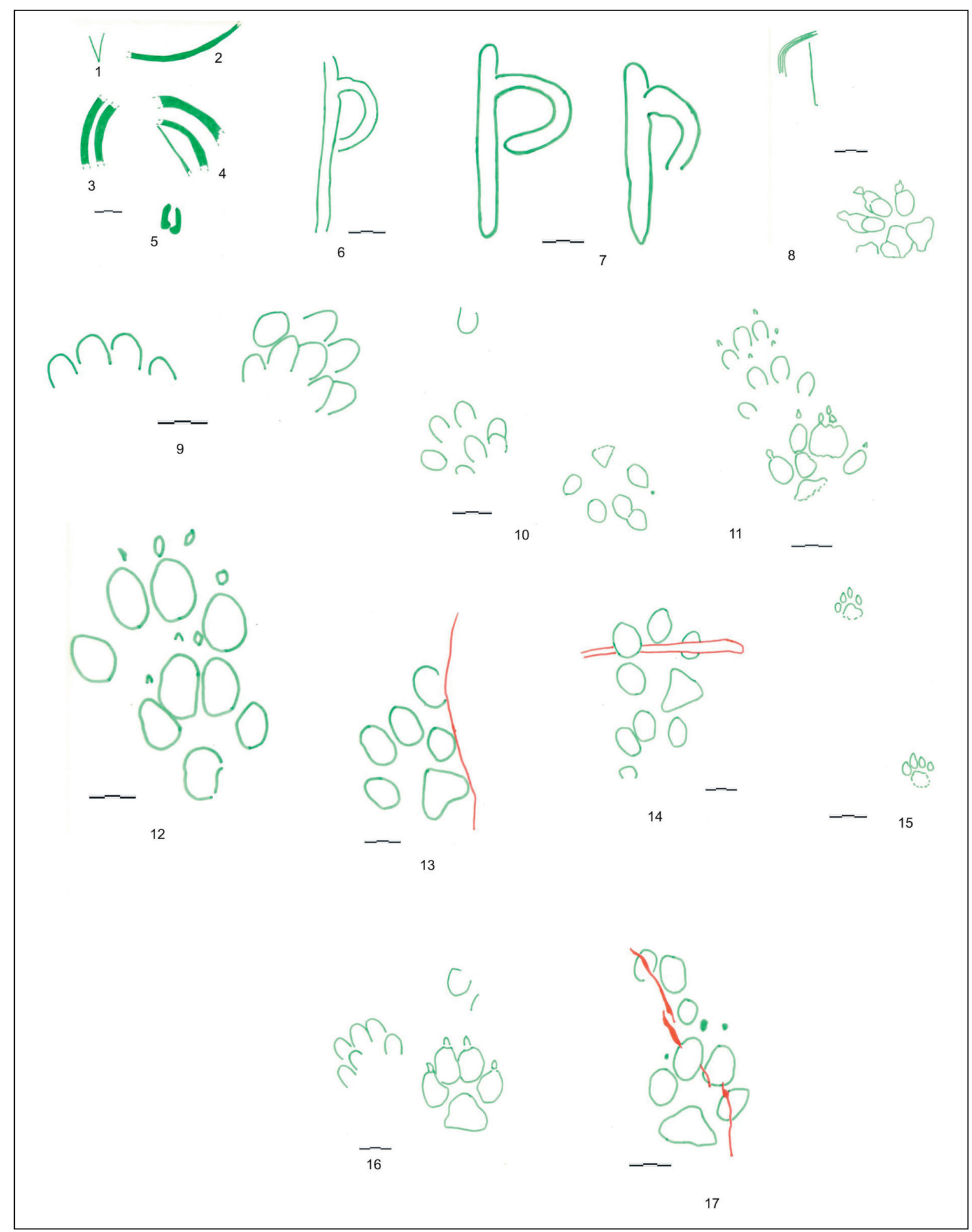

Figura 14. Grafitos y marcas.

Del conjunto de grafitos, las letras son interesantes porque permiten el establecimiento de paralelos con otros yacimientos, siendo el más inmediato, el reconocido en el castro de esta localidad (VILLAR, ROBINEAU 2010: 141). Las letras identificadas en este alfar -V, P, S, N- fueron reconocidas en ánforas de yacimientos castreños con niveles de época romana geográficamente próximos, como Santa Trega, Castro de Vigo, Toralla, O Neixón o A Lanzada (NAVEIRO 1985-86). Si bien aquí se identificaron sobre materiales de construcción, la semejanza de los grafitos podría indicar un origen común de ambas 
producciones, coincidiendo con una producción diversificada del alfar en un momento no tardío, constituyendo una nueva perspectiva de esta actividad económica en el Noroeste. La identificación de motivos de $\mathrm{S}$ y $\mathrm{P}$ en tegulae de la villa y necrópolis de Toralla (Vigo) (VIEITO COVELO, PÉREZ LOSADA, FERNÁNDEZ 2008: 759) podría indicar una comercialización en el entorno próximo de la producción de este alfar.

Las impresiones de grupos de dedos parecen corresponder a un gesto consciente al no encontrar una explicación en la manipulación técnica del objeto -en este caso serían esperables varios grupos de impresiones y no solamente de las yemas de los dedos. La presencia de huellas de perro en ocasiones superpuestas o combinadas con las anteriores resulta confusa en cuanto a la definición de los dos tipos y el análisis del valor como marca de alfar o no. Los materiales de construcción pueden reunir diversas marcas en una pieza.

\section{FunCIONALIDAD Y CRONOLOGÍA DEL ALFAR}

Según los datos expuestos resulta evidente que nos encontramos ante un tipo de yacimiento poco documentado al Norte del Miño, relacionado con una actividad económica como es la producción cerámica, pudiendo afirmar que representaba un centro importante que sin duda, superaba el ámbito doméstico y muy posiblemente local, cuestión que a partir de ahora deberá rastrearse en los yacimientos del entorno.

La diversificación de la producción de este alfar coincide con la conocida en otros centros alfareros similares de época romana, como los situados en estuarios portugueses de los ríos Tajo y Sado, siendo los recipientes anfóricos y los materiales de construcción las bases de la actividad, completada con objetos de uso doméstico, como vajillas de cocina y otras de mesa, con imitaciones de piezas originales de otras áreas geográficas.

A pesar del importante nivel de destrucción documentado en los restos estructurales, podemos señalar algunas áreas de actividades propias de un centro cerámico. El muro pétreo documentado actúa como eje diferenciador de éstas, quedando patente que la dimensión de este centro productivo superaba la del espacio de intervención, extendiéndose hacia el Este, Norte y Sur; es decir, estamos en una parte marginal del centro, situado delante de la playa de la Madorra.

El muro documentado -dirección E/O-, muy posiblemente se completaría con un tabique de materia vegetal y barro que sustentaría una techumbre al Sur del mismo, quedando abierto al Norte, donde se situaría el patio de trabajo y decantación de arcillas, con diversos acopios de arcillas claras, rosadas o grises. Esta hipótesis se apoya en el hecho de que a ambos lados del muro identificamos restos de elementos vegetales carbonizados, indicando una posible causa de destrucción por fuego.

Se conocen barras de arcilla en el litoral de Monteferro-Patos, próximas al alfar. Si bien el análisis de las arcillas todavía es un trabajo pendiente, la actividad de este alfar representa el origen de una actividad económica que llegó a la actualidad en el municipio de Nigrán, como productor de ladrillos y tejas, concentrando varios hornos industriales o telleiras que aprovechaban los barros locales, activos hasta mediados del S. XX. 
En este patio también se localizan las piletas de amasado y decantación, a base de ladrillos de tipo lydium. Fragmentos de piezas rotas durante el proceso de fabricación se encontraban en la base de algunos acopios.

Al Norte, la presencia de basas de pilares dejando un paso de $70 \mathrm{~cm}$ de anchura, pavimento de esquisto y zócalo indicarían una puerta o acceso a otra área que desconocemos al situarse en el solar contiguo por el Norte.

Al SO del muro y delante de la playa, la continuidad del alfar queda patente por un área al aire libre con funciones de secadero, constituida por restos de un pavimento rústico formado por fragmentos de tegulae y ladrillo asentados en una gruesa capa de arcilla para aislar de la humedad.

También al Sur del muro pero al Este, existiría un área prácticamente arrasada en la actualidad, relacionada con una estancia cubierta y de uso incierto -doméstico o almacenaje- pues casi todos los hallazgos de cerámicas domésticas proceden de esta área. La presencia de una basa para un pilar / biga de sustentación, implica la existencia de una techumbre en esta área, apreciándose que el suelo fue preparado previamente mediante la extensión de una fina capa de arcilla sobre el sustrato natural de arenas y gravas.

Más hacia el SE, podemos hablar de un espacio relacionado con centros de calor que pudieron formar parte de los hornos cerámicos, casi sin restos estructurales asociados, salvo un murete, en la misma dirección SE/NO pero sin permitir mayores apreciaciones. Con una estructura de cubeta excavada en la misma tierra, rellenada con una gruesa capa de arcilla, cubierta por una tégula sobre la que se haría fuego. Estas dos estructuras, espacialmente juntas, podrían formar parte del infierno de un horno.

El resto de la franja Sur resultó arqueológicamente estéril y todo parece indicar que las estructuras restantes del alfar se prolongaban hacia el Este. Anteriores intervenciones de urgencia en la Rúa do Arco, lindante con la finca por el Este (Fig. 1) sacaron a la luz informaciones en este sentido, sobre unas estructuras pétreas con estancias rectangulares, canales de aguas y pavimentos de losas grandes. Entre los materiales se recuperaron restos de tegulae, ánforas, ímbrices, cerámicas domésticas comunes, terra sigillata y vidrio; destacando el hallazgo de fragmentos de ánfora palestiniana, datada en los S. V-VI dC (Castro Carrera 1993a).

También en el número 13 de la misma Rúa do Arco otra intervención de urgencia constata abundantes restos materiales de época romana -fragmentos de ánfora, tegulae, cerámica común doméstica y escorias de fundición con restos de vidrio pegados-, llevan a la confirmación de la extensión del poblamiento tardo romano en un momento de desarrollo del comercio marítimo. En relación con las estructuras documentadas, se interpretan como espacios no de habitación doméstica sino destinados a la actividad económica, concretamente la producción de vidrio (CASTRO CARRERA 1993b).

En relación a la cronología y período de actividad del centro alfarero, la información aportada por los restos materiales plantea un inicio de la actividad del alfar en la segunda mitad del S. I - II dC, si nos apoyamos en la presencia de una fíbula aucissa, tipo antiguo de cronología comprendida entre los S. I aC - II dC (LAGE PILLADO 2004: 103-106), además de los tipos anfóricos Dressel 14. 
Esta actividad pudo continuar hasta el $\mathrm{S} \mathrm{V} \mathrm{dC,} \mathrm{según} \mathrm{las} \mathrm{cronologías} \mathrm{de} \mathrm{las} \mathrm{ánfo-}$ ras lusitanas, con las que se relacionan tipos aquí presentes (FABIÂO 2004; MORAIS 2005; MORAIS, FABIÂO 2007). Los motivos que llevaron a la suspensión de actividad no resultan evidentes, si bien se constata un fuerte arrasamiento del establecimiento, incluyendo un incendio. Es posible que en momentos tardíos y antes de su abandono tuviese una fase final de petrificación de las estructuras, evidenciada en la aplicación de pavimentos de piedra local de esquisto sobre los originales de ladrillos.

Posteriormente el centro productivo sería abandonado y muy posiblemente esquilmado de todo tipo de material que pudiera ser reutilizado en otras construcciones, lo que explicaría la escasa presencia de piezas y restos completos junto a alto grado de fragmentación de los recuperados. La última modificación de las estructuras vino en el S. $\mathrm{XX}$ con la construcción del viejo inmueble de piedra en el centro de este espacio -Estela Maris-, junto a la explosión del sector inmobiliario de los ochenta con el levantamiento de nuevos inmuebles en los solares del contorno.

Por otra parte, la información acerca del poblamiento romano en Panxón, encuentra sólidos argumentos en la existencia de un asentamiento castreño en la pequeña península del Monte del Castro (GA 36035057) (COSTAS GOBERNA, HIDALGO CUÑARRO, SOBRAL, VIÑAS CUÉ 1996; VILLAR, ROBINEAU 2010) con elementos de romanización (mosaico, ánforas, monedas...) y que pudo tener una larga vigencia, superando espacialmente la pequeña península y extendiéndose al Este y Norte por delante del litoral de la playa de la Madorra.

Tenemos por tanto, informaciones inéditas para el Norte del Miño, que en adelante, deberán valorarse para intentar discernir si estamos ante un alfar con una producción de consumo estrictamente local o para el comercio en un área geográfica más o menos próxima -ría de Vigo, O Grove... (?)- por vía marítima (?), teniendo en cuenta la oportunidad de un puerto en esta villa, por el que recibir y enviar mercancías. Los tipos anfóricos aquí identificados se destinaban a productos piscícolas -únicamente este uso es dudoso para el tipo Lusitana 9 (CORDEIRO, QUARESMA 2014)-, resultando coherentes con el entorno geográfico y poblamiento en la época, en la que la pesca sería un recurso fundamental.

Otras referencias de actividad alfarera romana en el entorno próximo revelan importantes diferencias con este de Panxón, en Nigrán. La localización de hornos de cocción de producciones domésticas es un hecho conocido. En la cercana Península del Morrazo, concretamente en la municipio de Cangas, la construcción del corredor que une esta localidad con Bueu, atravesando la península de Norte a Sur por el paso natural de A Porteliña, permitió la localización del horno de O Redolliño (ABOAL FERNÁNDEZ, CASTRO HIERRO, RODRÍGUEZ MARTÍNEZ 2008). Se trata de una estructura rectangular, exenta y sin contexto. Los materiales asociados a su producción son tegulae y ladrillo. Se le supone relación con una villa. Su cronología es tardía, entre los S. III - V dC.

Muy próximo a este, en el municipio de Bueu, al Norte de la Península del Morrazo y en la ría de Pontevedra se localiza el yacimiento de Pescadoira, próximo a la playa. Vinculado a una instalación salazonera y villa romana, este horno circular se destinaba exclusivamente a la fabricación de ánforas para el comercio del producto piscícola y 
salsero. Cronológicamente se sitúa entre los S. I - IV dC (VIÑAS CUE 2000; DÍAZ GARCÍA 2000).

Por tanto, es evidente que la finalidad y significado económico de estas estructuras difiere del alfar de Panxón, que muestra una producción diversificada y una instalación económica compleja, con áreas de actividades diferentes. La distribución de los productos aquí elaborados habrá que rastrearla a partir de esta información en el entorno próximo.

\section{Bibliografía}

ABOAL FERNÁNDEZ, R.; CASTRO HIERRO, V.; RODRÍGUEZ MARTÍNEZ, R. 2008. "El horno romano de O Redolliño (Cangas, Pontevedra)", Cuadernos de Estudios Gallegos LV, $\mathrm{n}^{\circ}$ 121: 93-108.

ALCORTA IRASTORZA, E. J. 2001. Lucus Augusti. II. Cerámica común romana de cocina y mesa hallada en las excavaciones de la ciudad. Fundación Pedro Barrié de la Maza.

ALMEIRA, R.R.; CORDEIRO RAPOSO, J.M. 2014. "Almagro 50 (Lusitania occidental)" en Amphorae ex Hispania. Paisajes de producción y consumo (http://amphorae.icac.cat/tipol/view/14).

BELTRÁN LLORÍS, M. (1970): Las ánforas romanas en España, Anejo a Caesaraugusta VIII.

BERNAL, D.; LAGÓSTENA, L. (Ed) 2004. FIGLINAE BAETICAE. Talleres alfareros y producciones cerámicas en la Bética romana (ss. II aC-VII dC). Vol. I. BAR 1266.

BERNARDES, J.P.; MORAIS, R.; VAZ PINTO, I.; DÍAS, R. 2011. "A olaria baixo imperial do Martinhal (Sagres, Portugal)” en BERNAL, D.; JUÁN, L.C.; BUSTAMANTE, M..; DIAZ, J.J.; SÁEZ, A.M. (Ed) (2011): Hornos, talleres y focos de producción alfarera en Hispania. I Congreso Internacional de la SECAH, Cádiz 2011. Monografías Ex Officina Hispana 1: 317-329.

CARDOSO, G.; RODRIGUES, S. 2005. "Olaria romana de Morraçal de Ajuda (Peniche, Portugal)" en A Presença Romana na Regiâo Oeste. Bombarral: 88-107.

CASTRO CARRERA, J. C. 1993a. Escavación arqueolóxica de urxencia en área no solar da Rúa do Arco de Panxón. Memoria técnica. Dirección Xeral de Patrimonio Cultural. Consellería de Cultura, Comunicación Social e Turismo. Xunta de Galicia. Inédito.

CASTRO CARRERA, J.C. 1993b. Informe das sondaxes feitas no inmoble $n^{\circ} 13$ da rúa do Arco de Panxón (Nigrán). Dirección Xeral de Patrimonio. Consellería de Cultura. Xunta de Galicia. Inédito.

CASTRO PAREDES, I. 2001. "Las fíbulas aucissas en el Castro de Santa Trega (A Guarda, Pontevedra). Estúdio y catálogo de piezas”, Gallaecia 20: 149-165.

CORDEIRO RAPOSO, J.M.; QUARESMA, J.C. 2014. "Lusitania 9 (Lusitania occidental)" en Amphorae ex Hispania. Paisajes de producción y consumo (http://amphorae.icac.cat/tipol/view/23).

CORDEIRO RAPOSO, J.M.; VIEGAS, C. 2013. "Dressel 14 (Lusitania occidental)" en Amphorae ex Hispania. Paisajes de producción y consumo (http://amphorae.icac.cat/tipol/view/13).

COSTAS GOBERNA, J.; HIDALGO CUÑARRO, J.M.; SOBRAL, J.M.; VIÑAS CUÉ, R. 1996. Raíces de Nigrán, dede os petroglifos ata o arco visigodo. Concello de Nigrán.

DÍAZ GARCÍA, F. 2000. Excavación arqueológica en área en el solar $n^{\circ} 7$ de la Avenida Montero Ríos (Bueu, Pontevedra). Servicio de Arqueoloxía. Dirección Xeral de Patrimonio Cultural. Xunta de Galicia. Memoria. Inédita.

FABIÂO, C. 2004. "Centros oleiros da Lusitania. Balanço dos coñecimentos e perspectivas de investigação”. Actas del Congreso Internacional FIGLINAE BAETICAE. BAR International Series 1266: 379-410.

FABIÂO, C. 2008. "Las ánforas de Lusitania” en Cerámicas Hispanorromanas. Un estado de la cuestión: 725-745.

GARCÍA VARGAS, E.; LAVADO FLORIDO, M.L. 1995. "Ánforas alto, medio y bajo imperiales producidas en al alfar de Puente Melchor (Villanueva, paso a nivel: Puerto Real, Cádiz)”, Spal, 4: 215-228. 
JUAN TOVAR, L. C. 1990. "Alfares y vías de comunicación en la Hispania Romana”. La Red Viaria romana en Hispania. Zaragoza: 293-301.

LAGE PILLADO, M. 2004. Fíbulas galaico-romanas do Castro de Viladonga. Xunta de Galicia.

MÁRQUEZ VILLORA, J. C. 1999. El comercio romano en el Portus Ilicitanus. El abastecimiento exterior de productos alimentarios (S. I a.C.-V d.C.). Publicaciones de la Universidad de Alicante.

MARTÍNEZ CORTIZAS, A.; COSTA CASAIS, M. 1997. "Indicios de variaciones del nivel del mar en la ría de Vigo durante los últimos 3000 años", Gallaecia 16: 23-47.

MORAIS, R. (2005): Autarcia e comercio em Bracara Augusta. Excavaçôes Arqueológicas 2. Universidade do Minho. Braga. Portugal.

MORAIS, R.; FABIÂO, C. 2007. "Novas produções de fabrico lusitano: problemáticas e importância econômica”. Actas del Congreso Internacional CETARIAE. BAR International Series 1686: 127133.

NAVEIRO, J. 1985-86. "Marcas de ánfora en Galicia: la problemática de los grafitti", Pontevedra Arqueológica II: 201-208.

NAVEIRO, J. 1991. El comercio antiguo en el noroeste peninsular. Museo Castelo de San Antón. Monografías $n^{0} 5$. A Coruña.

PÉREZ LOSADA, F. 1993. "Contribución ó estudio da cerámica de construcción na Galicia romana (I)". Galicia: da Romanidade á Xermanización. Homenaje a Fermín Bouza Brey. Santiago: 241-262.

REY CASTIÑEIRAS, M. J. 1990-91. "Cerámica indígena de los castros costeros de la Galicia occidental. Rías Bajas”, Castrelos III-IV: 141-167.

VIEGAS, C.; CORDEIRO RAPOSO, J.M.; VAZ PINTO, I. 2014. "Almagro 51c (Lusitania occidental)" en Amphorae ex Hispania. Paisajes de producción y consumo (http://amphorae.icac.cat/tipol/ view/75).

VIEITO COVELO, S.; PÉREZ LOSADA, F.; FERNÁNDEZ, A. 2008. "El material cerámico de construcción en la villa y necrópolis de Toralla: tipología y usos" en FERNÁNDEZ OCHOA, C.; GARCÍA ENTERO, V.; GIL SENDINO, F. (Ed): Las Villae Tardorromanas en el Occidente del Imperio: arquitectura y función. IV Coloquio Internacional de Arqueología. Gijón 2006: 755-766.

VILLAR QUINTEIRO, R. 2005. Informe das actuacións previas no entorno do BIC arco visigodo de Panxón. Nigrán.Pontevedra. Dirección Xeral de Patrimonio Histórico da Consellería de Cultura, Xunta de Galicia. Inédito.

VILLAR QUINTEIRO, R. 2008. "Intervención arqueológica valorativa na rúa Tomás Mirambel nº 8. Panxón. Nigrán”, "Escavación arqueolóxica en área na rúa Tomás Mirambel nº 8. Panxón. Nigrán”, Actuacións Arqueológicas. Ano 2006. Consellería de Cultura e Deporte. Xunta de Galicia: 157-160.

VILLAR QUINTEIRO, R.; ROBINEAU, N. 2010. "Castro de Panxón (Nigrán, Pontevedra). Nuevos datos y evaluación de su estado actual”, Gallaecia 29: 137-144.

VIÑAS CUE, R. 2000. Sondeos arqueológicos manuales y mecánicos en el solar $n^{0} 7$ de la Avenida Montero Ríos (Bueu, Pontevedra). Servicio de Arqueoloxía. Dirección Xeral do Patrimonio Cultural. Xunta de Galicia. Memoria. Inédita.

V.V.A.A. 2006. Produçâo e Comercio de preparados piscícolas durante a Proto - Historia e a época romana no occidente da Península Ibérica. Simposio Internacional. Setúbal Arqueológica, 13. 